Indonesian Journal of Physics

Vol 19 No. 3, July 2008

\title{
Structural Characteristics of Carbon Nanotubes Fabricated Using Simple Spray Pyrolysis Method
}

\author{
Khairurrijal $^{\#}$, Mikrajuddin Abdullah, Memoria Rosi, and Fatimah A. Noor \\ Physics of Electronic Materials Research Division \\ Faculty of Mathematics and Natural Sciences \\ Institut Teknologi Bandung \\ Jl. Ganesa 10, Bandung 40132, Indonesia \\ \# e-mail address: krijal@fi.itb.ac.id
}

\begin{abstract}
A simple spray pyrolysis method has successfully used to synthesize carbon nanotubes (CNTs). Their structural characteristics were characterized by employing field-emission scanning electron microscopy (FE-SEM), energy dispersive X-ray (EDX) analysis, and X-ray diffraction (XRD) methods. FE-SEM images confirmed that the diameters of CNTs were in the range of 20 to $80 \mathrm{~nm}$. The average diameter of CNTs increased considerably as the growth temperature increased (above $700{ }^{\circ} \mathrm{C}$ ). The changes in growth time and ferrocene mass altered the average diameter of CNTs slightly. EDX analysis and XRD patterns indicated that $\mathrm{Fe}_{2} \mathrm{O}_{3}$ and $\mathrm{Fe}_{3} \mathrm{O}_{4}$, which originate from the oxidation of ferrocene catalyst, are the main impurities of the CNTs. The concentrations of $\mathrm{Fe}_{3} \mathrm{O}_{4}$ and $\mathrm{Fe}_{2} \mathrm{O}_{3}$ became lower and higher, respectively, for the growth temperatures higher than $700{ }^{\circ} \mathrm{C}$ because $\mathrm{Fe}_{2} \mathrm{O}_{3}$ is the most stable at high temperatures.
\end{abstract}

Keywords: Carbon nanotubes (CNTs), Spray pyrolysis, scanning electron microscopy (SEM), Energy dispersive XRay (EDX), X-Ray diffraction (XRD), Photoluminescence (PL).

\section{Introduction}

Carbon nanotubes (CNTs), which can be metallic or semiconducting, are very attractive materials because of their tube-like structure. This structure, which depends on the degree of graphitization, the helicity and the diameter, determines the essential characteristics of CNTs that seem to be promising for a variety of applications, such as supercapacitor, nanoscale sensors, hydrogen storage, field-emission displays, nanostructured composite materials, and elements of new nanoscale logic circuits $^{1-9)}$.

Several methods have been used to fabricate CNTs including arc discharge, laser ablation, and plasma-enhanced chemical vapor deposition (PECVD) ${ }^{10-12)}$. However, these methods have some limitations especially if used for large scale of fabrication. Therefore, further studies have been directed toward fabrication of CNTs using alternative methods such as a simple one known as spray pyrolysis. Previous studies have shown that the spray pyrolysis method is easier to control, safer, has lower energy consumption compared to other methods, and prevents the formation of large amounts of amorphous carbon through continuous generation of catalytic particles throughout the entire growth cycle ${ }^{13,14)}$. In general, the spray pyrolysis method employs a nebulizer producing aerosol and a carrier gas to transport the aerosol into the hot zone where reactions to synthesize CNTs take place. Very recently, it has been reported pyrolysis-assisted CVD, which is a new method for production of CNTs ${ }^{15)}$.

In this paper, we present the fabrication of CNTs using a modified spray pyrolysis method without carrier gas. A nebulizer and a carrier gas in the general spray pyrolysis method are replaced by a syringe. Benzene $\left(\mathrm{C}_{6} \mathrm{H}_{6}\right)$ was selected as a carbon source and ferrocene $\left(\mathrm{Fe}\left(\mathrm{C}_{5} \mathrm{H}_{5}\right)_{2}\right)$ was the catalyst for growing CNTs as reported in previous papers ${ }^{16-18)}$. Reaction parameters such as growth temperature, growth time, and ferrocene mass were studied to obtain high quality CNTs. Structural characteristics of CNTs were investigated by using three characterization techniques including field-emission scanning electron microscopy (FE-SEM), energy dispersive X-ray (EDX) analysis, and X-ray diffraction (XRD).

\section{Experimental}

A modified spray pyrolysis apparatus used for the fabrication of CNTs is schematically illustrated in Figure 1. The apparatus consists of three important components: a sprayer, a single hot zone, and an exhaust. The sprayer is a syringe composed of a nozzle, a container where a solution is stored, and a plunger for drawing in a solution and then pushing it out. Therefore, the syringe generates an aerosol from a solution and thrust the aerosol directly. The single hot zone is a long stainless-steel pipe heated inside a tubular furnace. The aerosol then enters the single hot zone where CNTs are produced. The exhaust is to draw off by-product gases during the fabrication of CNTs.

The precursor solution was a mixture of ferrocene (98\% purity; Aldrich) in $10 \mathrm{ml}$ benzene (BR-0220 Tedia). The growth temperature, which is the desired temperature for growing CNTs in the single hot zone, was controlled by a proportionalintegral-differential (PID) controller. A natural cooling process down to room temperature was done 
after growing the CNTs. Finally, black powders were taken from inside the pipe.

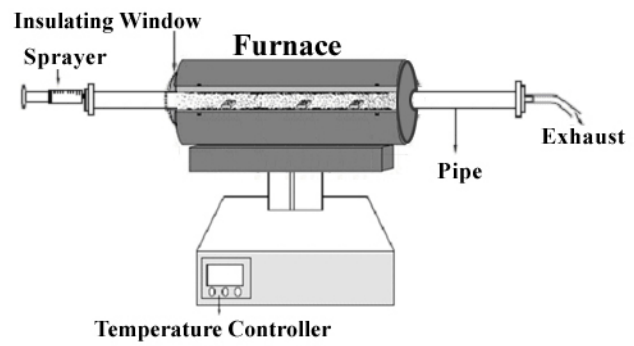

Figure 1. Simple spray pyrolysis apparatus for the fabrication of carbon nanotubes.

Three reaction parameters, i.e. ferrocene mass, growth temperature, and growth time, were varied. The ferrocene masses were $0.2,0.4,0.6,0.8$, and 1.0 g. The growth temperatures were set at $650,700,750$, and $800{ }^{\circ} \mathrm{C}$. The growth times with the temperature profile illustrated in Figure 2 were 0, 30, 60, 120 and $150 \mathrm{~min}$. These parameters were combined to find a condition resulting in high quality CNTs.

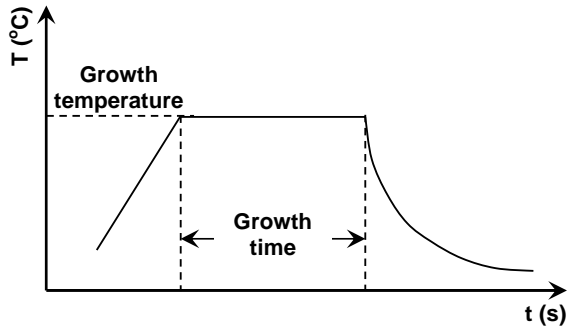

Figure 2. Temperature in the single hot zone as a function of time.

As-grown CNTs were then characterized by employing Hitachi S-5000 and JEOL JSM-6360 LA for SEM images and EDX analysis, respectively. Xray diffractograms were obtained by Rigaku-Denki RINT2000. Photoluminescence spectra were measured by using Shimadzu RF-5300 PC with a source excited at $250 \mathrm{~nm}$.

\section{Results and Discussion}

\subsection{SEM images}

Figure 3 gives FE-SEM images of as-grown CNTs for various ferrocene masses at the growth temperature of $850^{\circ} \mathrm{C}$ and for the growth time of 0 min. It is found that the average diameter of CNTs are about 30-50 nm and almost does not depend on the ferrocene mass, which is inconsistent with that reported in Ref. 17. This finding implies that the ferrocene masses used here is insignificant to affect the diameter of CNTs.
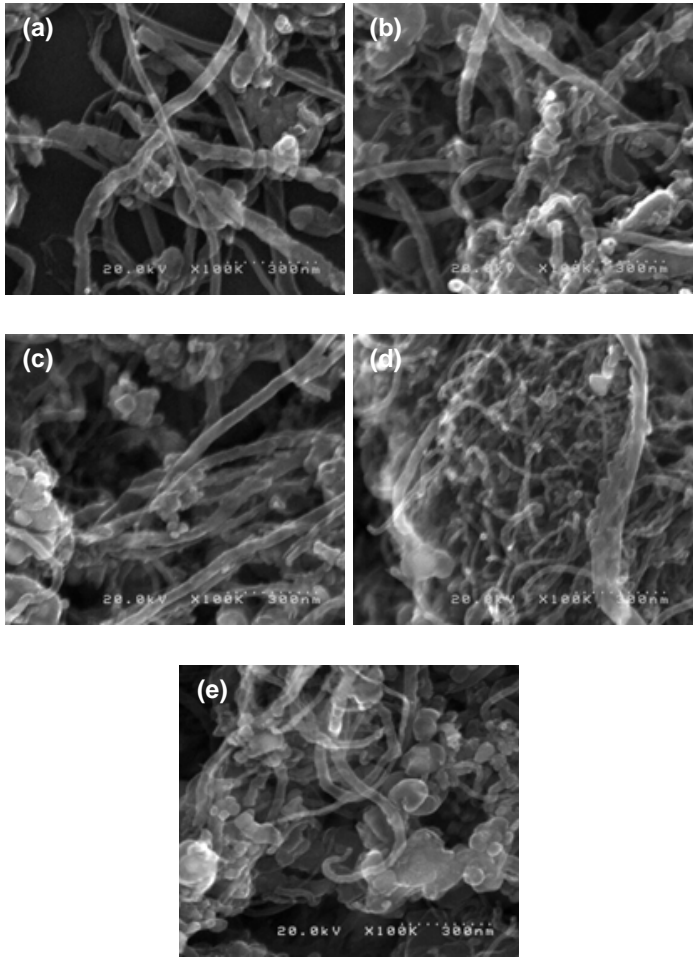

Figure 3. FE-SEM images of as-grown CNTs for different ferrocene masses: (a) $0.2 \mathrm{~g}$, (b) $0.4 \mathrm{~g}$, (c) 0.6 g, (d) $0.8 \mathrm{~g}$, and (e) $1.0 \mathrm{~g}$. (the growth temperature of $850^{\circ} \mathrm{C}$ and the growth time of $0 \mathrm{~min}$ ).

FE-SEM images of as-grown CNTs for different growth times at the temperature of $850{ }^{\circ} \mathrm{C}$ and using $0.6 \mathrm{~g}$ ferrocene are demonstrated in Figure 4. It is seen that the average diameter of CNTs, which is about $30-50 \mathrm{~nm}$, is almost unchanged with increasing growth time.
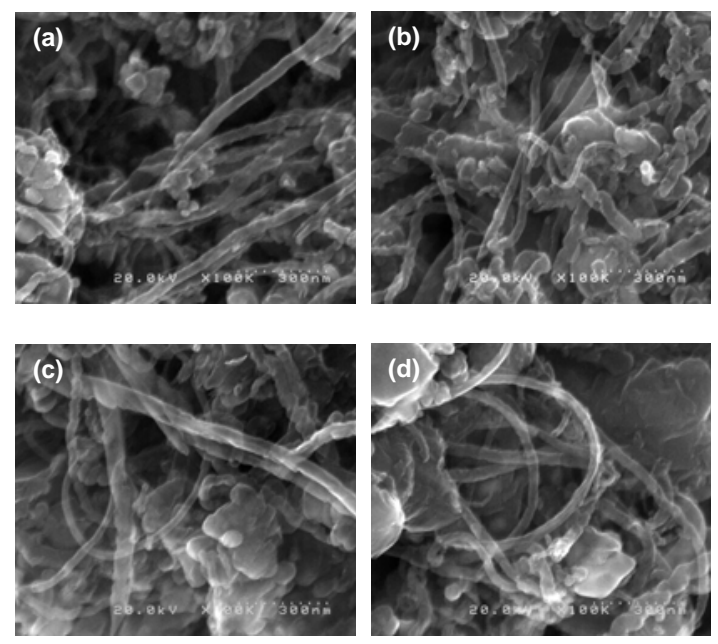


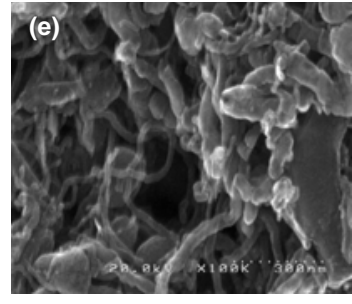

Figure 4. FE-SEM images of as-grown CNTs for several growth time: (a) $0 \mathrm{~min}$, (b) $30 \mathrm{~min}$., (c) 60 min., (d) $120 \mathrm{~min}$. , and (e) $150 \mathrm{~min}$. (at $850^{\circ} \mathrm{C}$ and using $0.6 \mathrm{~g}$ ferrocene).

Figure 5 shows FE-SEM images of as-grown CNTs for several growth temperatures. Below $700{ }^{\circ} \mathrm{C}$, the as-grown CNTs have the diameters in the range of 20-50 $\mathrm{nm}$. However, at the temperatures above 700 ${ }^{\circ} \mathrm{C}$, the diameters become $30-80 \mathrm{~nm}$. This result suggests that CNT entanglement occurred, which is in agreement with the observation in Ref. 19. Moreover, at $800{ }^{\circ} \mathrm{C}$, the as-grown CNTs demonstrate well alignment profile with lesser granules.
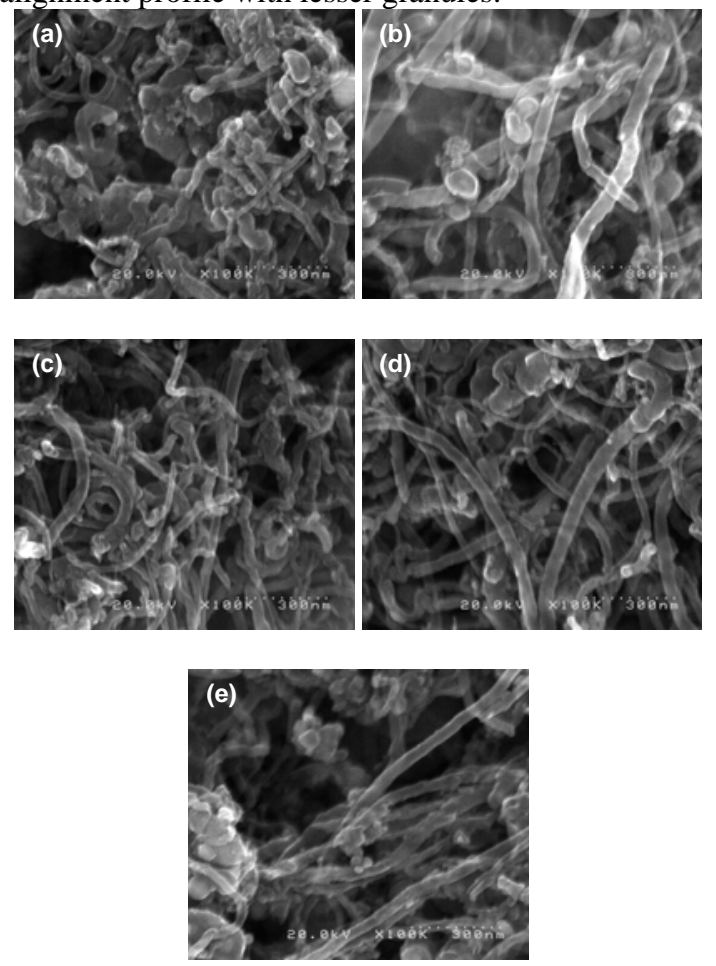

Figure 5. FE-SEM images of as-grown CNTs for various growth temperatures: (a) $650{ }^{\circ} \mathrm{C}$; (b) $700{ }^{\circ} \mathrm{C}$; (c) $750{ }^{\circ} \mathrm{C}$; (d) $800{ }^{\circ} \mathrm{C}$, and (e) $850{ }^{\circ} \mathrm{C}$ using $0.6 \mathrm{~g}$ ferrocene and the growth time of $0 \mathrm{~min}$.

\subsection{EDX analysis}

Elements and compounds contained in CNTs were analyzed by employing EDX. Table 1 shows the fractions of $\mathrm{C}$ and other impurities in CNTs grown at $850^{\circ} \mathrm{C}$ and the growth time of $0 \mathrm{~min}$ for various ferrocene masses. It is seen that high purity CNTs are produced by using 0.2 and $1.0 \mathrm{~g}$ ferrocene. $\mathrm{FeO}$ is the main impurity originating from the use of ferrocene as a catalyst for synthesizing the CNTs. In addition, there are other impurities (6.16 \%) in the CNTs produced by using $0.2 \mathrm{~g}$ ferrocene.

Table 1. Content analysis of CNTs for different ferrocene masses.

\begin{tabular}{cccc}
\hline \multirow{2}{*}{$\begin{array}{c}\text { Ferrocene } \\
\text { Mass (g) }\end{array}$} & \multicolumn{3}{c}{$\begin{array}{c}\text { Elemental/Compound } \\
\text { Fraction (\%) }\end{array}$} \\
\cline { 2 - 4 } & $\mathrm{C}$ & $\mathrm{FeO}$ & Others \\
\hline 0.2 & 78 & 16 & 6 \\
\hline 0.4 & 73 & 27 & 0 \\
\hline 0.6 & 72 & 28 & 0 \\
\hline 0.8 & 73 & 27 & 0 \\
\hline 1.0 & 82 & 18 & 0 \\
\hline
\end{tabular}

Table 2 exhibits contents of CNTs synthesized at different growth times (at $850^{\circ} \mathrm{C}$ and using $0.6 \mathrm{~g}$ ferrocene). It seems that the increase of growth time influences the $\mathrm{C}$ content (purity) of CNTs insignificantly.

Table 2. Content analysis of CNTs for different growth times.

\begin{tabular}{cccc}
\hline \multirow{2}{*}{$\begin{array}{c}\text { Growth Time } \\
\text { (min.) }\end{array}$} & \multicolumn{3}{c}{$\begin{array}{c}\text { Elemental/Compound } \\
\text { Fraction (\%) }\end{array}$} \\
\cline { 2 - 4 } & $\mathrm{C}$ & $\mathrm{FeO}$ & Others \\
\hline 0 & 72 & 28 & 0 \\
\hline 30 & 67 & 33 & 0 \\
\hline 60 & 79 & 21 & 0 \\
\hline 120 & 72 & 28 & 0 \\
\hline 150 & 79 & 21 & 0 \\
\hline
\end{tabular}

\subsection{XRD patterns}

The XRD patterns in Figure 6 confirm that the powders prepared by using several ferrocene masses are CNTs with (002) as a dominant orientation. The (101), (102), and (004) orientations, which are the minor ones, are observed in CNTs produced by using $0.2 \mathrm{~g}$ ferrocene. The peaks of (102) and (004) disappear when the ferrocene mass is increased to 0.4 , $0.6,0.8$, and $1.0 \mathrm{~g}$. These findings are agreed with observations reported in Ref. 20. Other peaks are corresponding to $\mathrm{Fe}_{2} \mathrm{O}_{3}$ (hematite) and $\mathrm{Fe}_{3} \mathrm{O}_{4}$ (magnetite) emanating from the oxidation of $\mathrm{Fe}$ in ferrocene. 


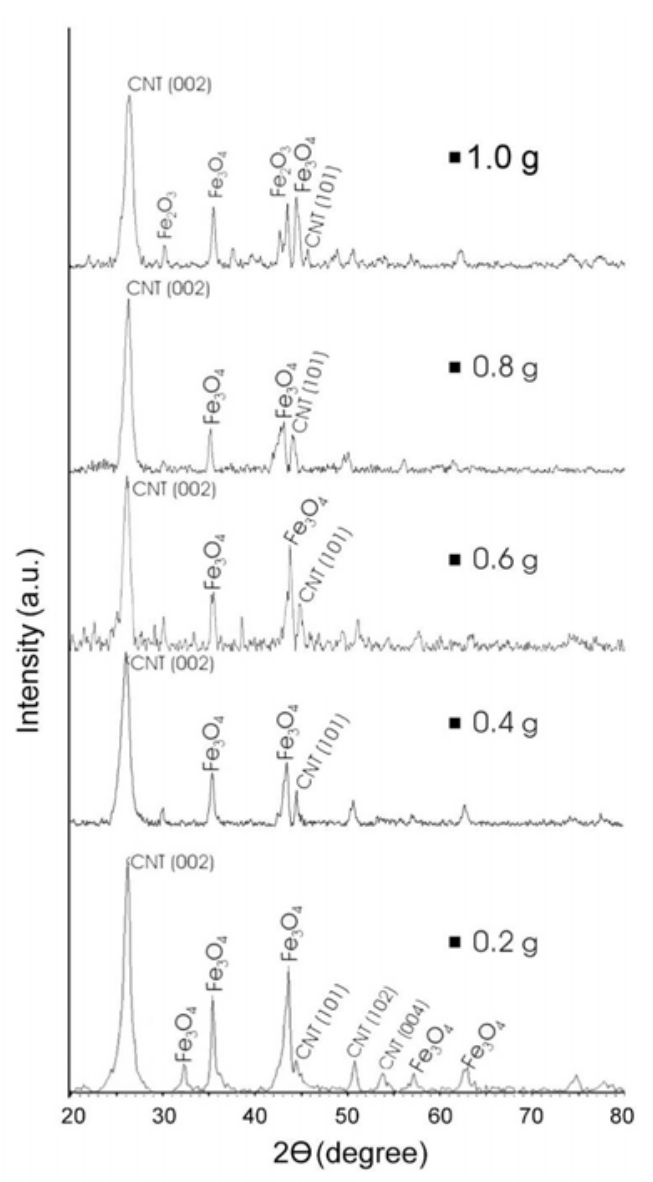

Figure 6. XRD patterns of as-grown CNTs prepared by using several ferrocene masses at $850^{\circ} \mathrm{C}$ and the growth time of $0 \mathrm{~s}$.

Figure 7 shows XRD patterns of as-grown powders prepared under various growth times. The powders are CNTs with (002) as a dominant orientation. The increase of growth time does not change the XRD peaks of (102) and (004) significantly. For the growth time in the range of 0 to $120 \mathrm{~min}$., the impurities are only from the oxidation of Fe forming $\mathrm{Fe}_{2} \mathrm{O}_{3}$ (hematite) and $\mathrm{Fe}_{3} \mathrm{O}_{4}$ (magnetite). More increase of the growth time (150 min.) results in a new species of carbide $\mathrm{Fe}_{3} \mathrm{C}$ and the loss of $\mathrm{Fe}_{2} \mathrm{O}_{3}$.

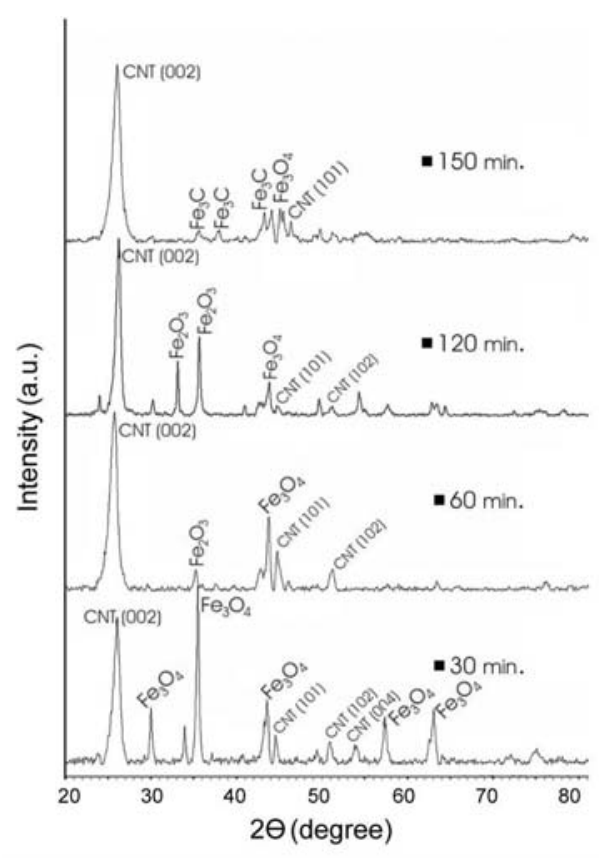

Figure 7. XRD patterns of as-grown CNTs prepared under several growth times at $850^{\circ} \mathrm{C}$ and $0.6 \mathrm{~g}$ ferrocene.

The XRD patterns obtained from CNTs grown at different growth temperatures also demonstrate three main diffraction peaks with (002) as a dominant peak and (101) and (004) orientations as minor ones (Figure 8). Other peaks are corresponding to $\mathrm{Fe}_{3} \mathrm{O}_{4}$ and $\mathrm{Fe}_{2} \mathrm{O}_{3}$, which are impurities to the CNTs. When the growth temperature is increased to $800^{\circ} \mathrm{C}$, the concentration of $\mathrm{Fe}_{3} \mathrm{O}_{4}$ becomes smaller and in contrast that of $\mathrm{Fe}_{2} \mathrm{O}_{3}$ increases because $\mathrm{Fe}_{2} \mathrm{O}_{3}$ is the most stable at high temperatures.

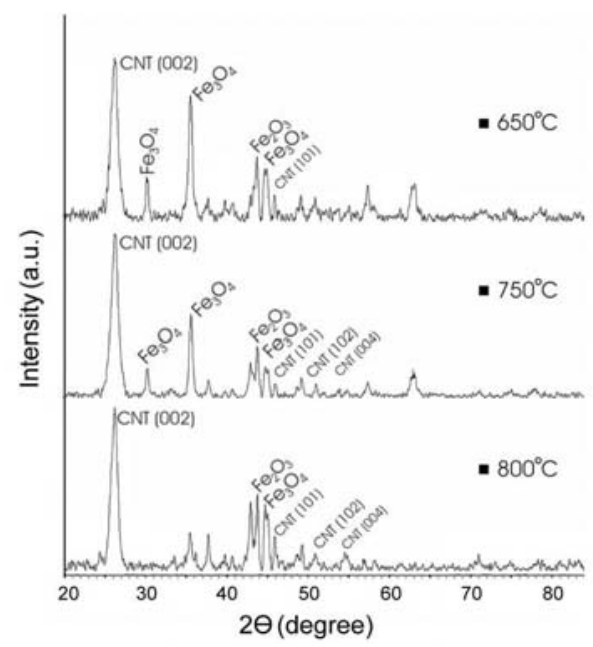

Figure 8. XRD patterns of as-grown CNTs prepared under several growth temperatures for $0.6 \mathrm{~g}$ ferrocene and the growth time of $0 \mathrm{~s}$. 
In general, all the XRD patterns show that the peaks of CNTs, especially for CNTs (002), are relatively symmetric compared to others. This indicates a good crystallite dimension and a longrange order ${ }^{21)}$. The presence of $\mathrm{Fe}_{3} \mathrm{O}_{4}$ and $\mathrm{Fe}_{2} \mathrm{O}_{3}$ from the XRD patterns indicates the impurities, which are consistent to EDX analysis.

\section{Conclusions}

Carbon nanotubes (CNTs) have successfully been grown by using the simple spray pyrolysis method and characterized by employing three characterization techniques. The diameters of CNTs were in the range of 20 to $80 \mathrm{~nm}$ as observed from FESEM images. The average diameter of CNTs increased significantly with increasing growth temperature (above $700{ }^{\circ} \mathrm{C}$ ). The changes in growth time and ferrocene mass altered the average diameter of CNTs insignificantly. EDX analysis and XRD patterns indicated that the CNTs have $\mathrm{Fe}_{2} \mathrm{O}_{3}$ and $\mathrm{Fe}_{3} \mathrm{O}_{4}$ impurities originating from the oxidation of ferrocene catalyst. As the growth temperature became higher than $700^{\circ} \mathrm{C}$, the concentrations of $\mathrm{Fe}_{3} \mathrm{O}_{4}$ and $\mathrm{Fe}_{2} \mathrm{O}_{3}$ decreased and increased, respectively, because $\mathrm{Fe}_{2} \mathrm{O}_{3}$ is the most stable at high temperatures.

\section{Acknowledgements}

This research was supported by the Ministry of Research and Technology of Republic of Indonesia through the Incentive Research Grant No. 30/RD/Insentif/PPK/1/2007 for 2 years (2007 and 2008).

\section{References}

1. M. Endo, M. S. Strano, and P. M. Ajayan, Carbon Nanotubes, Springer, Berlin, 2008.
2. C. Du, N. Pan, Nanotechnology, 17, 5314-5318, 2006.

3. S. Ghosh, A.K. Sood, and N. Kumar, Science, 299, 1042, 2003.

4. J. Kong et al., Science, 287, 622-625, 2000

5. H. M. Cheng, C. Liu, and Y. Y. Fan, Science, 286, 1127, 1997.

6. O. Zhou, H. Shimoda, B. Gao, S. Oh, L. Fleming, and G. Yue, Acc. Chem. Res. 35,1045, 2002.

7. A. F. Mamedov et al., Nat. Mater. 1, 190, 2002.

8. P. Avouris, Acc. Chem. Res. 35, 1026, 2002.

9. H. Dai, Acc. Chem. Res. 35, 1035, 2002.

10. Y. Saito, T. Yoshikawa, and M. Inagaki, Chem Phys. Letts., 204, 277, 1993.

11. F. Kokai et al., Chem. Phys. Letts. 322, 449, 2000.

12. Y. Hayashi, T. Negishi, and S. Nishino, J. Vac. Sci. Technol., A 19, 1796-1799, 2001.

13. M. Abdullah, F. Iskandar, and K. Okuyama, Proc. ITB Eng. Science, 36 B, 125-131, 2004,

14. L. P. Biró et al., J. Optoelectron. Adv. Mater. 5, 661 - 666, 2003.

15. P. Mahanandia et al., P. N. Vishwakarma, K. K. Nanda, V. Prasad, K. Barai, A. K. Mondal, S. Sarangi, G. K. Dey, and S. V. Subramanyam, Solid State Commun. 145 (2008) 143-148

16. Y. Y. Wei et al., Appl. Phys. Lett. 78, 1394, 2001.

17. L. Tapasztó et al., Carbon 43, 970, 2005.

18. M. C. Schnitzler and A. J. G. Zarbin, J. Nanopart. Res. 10, 585-597, 2008.

19. H. Liu et al., Diamond \& Related Materials, 17,) 313-317, 2008.

20. G. Alonso-Nuñez et al., Optical Materials, 29, 134-139, 2006.

21. H. Zhu et al., Materials Science and Engineering, 138, 101-104, 2007. 